\title{
Cytokines, Autoantibodies, and Complements in Active Systemic Lupus Erythematosus Patients from Javanese Population
}

\author{
Yuliasih $^{1,2}$, Lita Diah Rahmawati ${ }^{1,2}$, Putu Ayu Niken Amrita ${ }^{1}$, Setiati Widyaningrum ${ }^{1}$, Dodi Kriswanto ${ }^{1}$ \\ ${ }^{1}$ Department of Internal Medicine, Faculty of Medicine, Airlangga University, Surabaya, Indonesia. E-mail:yuli177@yahoo.com \\ 2 Rheumatology Division of Internal Medicine Department, Faculty of Medicine, Airlangga University, Surabaya, Indonesia
}

\begin{abstract}
Systemic Lupus Erythematosus (SLE) is an autoimmune disease that has various clinical manifestations. The SLE pathogenesis involves both innate and adaptive immunological components. The system is essentially determined by genetic factors that control certain clinical and serological manifestations. Genetic traits that determine the roles of cytokines, autoantibodies, and complements in SLE vary among ethnicities. The roles of TNF- $\alpha$, IL- 6 , anti-C1q, anti-dsDNA, C3, and C4 towards SLE activity need to be evaluated in the Javanese population. This study aimed to determine the correlation of TNF- $\alpha$, IL-6, anti-C1q antibodies, anti-dsDNA, C3, and C4 with SLE activity. Forty SLE patients were diagnosed based on the American College of Rheumatology (ACR) criteria. Disease activity was measured by the Systemic Lupus Activity Measure (SLAM) index. TNF- $\alpha$, IL-6, Anti-C1q, and anti-dsDNA levels were measured by ELISA, while MINIMEPH measured C3 and C4. Thirty-nine female and one male patient with SLE were diagnosed according to ACR criteria. The mean of SLAM score, anti-dsDNA, C3, and C4 levels was $20.98 \pm 6.7,224.96 \pm 298.6,68.70 \pm 37.08 \mathrm{mg} / \mathrm{dL}$, and $18.75 \pm 10.69 \mathrm{mg} / \mathrm{dL}$, respectively. Spearman's correlation test showed a positive correlation between TNF- $\alpha(r=0.971, p<0.001), I L-6(r=0.835, p<0.001)$, anti-C1q $(r=0.399, p=0.01)$, and disease activity (SLAM score) by using. The linear regression test for TNF- $\alpha$, IL-6, anti-C1q, and SLAM showed the strongest association for TNF- $\alpha(r=0.891, p<0.000)$. TNF- $\alpha, I L-6$, and anti-C1q were correlated to disease activity in SLE patients from the Javanese population.
\end{abstract}

Keywords: Systemic lupus erythematosus, tumor necrosis factor- $\alpha$, interleukin-6, biomarkers

\section{INTRODUCTION}

Systemic Lupus Erythematosus (SLE) is a chronic systemic inflammatory disease caused by the autoimmune mechanism. Systemic lupus erythematosus begins with a loss of immunological tolerance that initiates an auto-reactivity of effector T-cells and leads to an immunological response to antigens. This process involves various mechanisms, including autoantibody production, complement activation, immune complex formation, and leukocyte infiltration. Cytokine production in SLE patients certainly differs from that in healthy individuals. Cytokines are accountable in regulating SLE activity and in different organs involvement. ${ }^{1}$

The presence of self-antigens triggers the activation of Antigen-Presenting Cells (APC), T-cells, and $\mathrm{B}$-cells through a biochemical signal from cytokines such as IL- 6 and TNF- $\alpha$. TNF- $\alpha$ is a pleiotropic cytokine that presumably causes apoptosis, activates dendritic cells, and stimulates IL- 6 secretion. Studies reported that IL- 6 stimulates both T-cells and $B$-cells differentiation to become effector cells and synthesize anti-dsDNA and anti-C1q. This feature causes hyper-response towards autoantibodies and organ inflammation. ${ }^{1,2}$

Anti-C1q, C3, and $\mathrm{C} 4$ are generally found at a low level in SLE patients. This complement functions typically in the process of antigen clearance or immunological complex to prevent the over-reactivity of an immune response. Complement deficiency is one of the causes of SLE patient's susceptibility to an autoimmune reaction. A study on patients without hereditary $\mathrm{Clq}$ deficiency reported that anti-C1q was found in active SLE. C3 and C4 level also decreases due to high clearance of elevated immune complexes. ${ }^{2}$

Previous studies reported different results of disease activity, possibly due to the variety of ethnic groups. It is crucial to evaluate the roles of various cytokines, antibodies, and autoantibodies to disease activity in SLE. This study aimed to correlate TNF- $\alpha$, IL-6, anti-C1q antibodies, anti-dsDNA, and C3 \& C4 to disease activity, through measurement using by SLAM index in inactive SLE patients from the Javanese population.

\section{METHODS}

This study was a cross-sectional study performed in the Department of Internal Medicine, Dr. Soetomo 
General Hospital, Surabaya, between January and June 2013. All data were collected from the medical records of newly diagnosed SLE patients who met four of the revised 1997 ACR criteria. Each patient who consented to participate in this study filled out informed consent. This study has been approved by the Ethics Review Committee, Dr. Soetomo Hospital, with number 312/Panke.KKE/I/2013. Non-probability consecutive sampling technique was used to enroll subjects, considering the confounding and bias factors. Infectious patients with an indication of blood/urine/sputum culture indicate micro-organism infections were excluded. Patients who showed symptoms overlapping with other connective tissue diseases were also excluded in this study.

Forty patients with an age range of $30 \pm 8.1$ years, consisting of 39 females and one male newly-diagnosed SLE patients, were included in this study. ACR criteria were used for SLE diagnosis, and four out of the 11 measures were found.

The systemic Lupus Activity Measure (SLAM) index is a measuring instrument for assessing SLE disease activity by weighing each parameter between $0-3$. The total score is a sum of all parameters, and it ranges from 0 to 86. A higher score indicates a more active or severe illness. SLAM has an interlined reliability index of 0.86 and an interval of reliability of $0.73 .{ }^{3}$

Anti-C1q and anti-dsDNA levels were measured by the ELISA method. The examination was performed according to standard operating procedures. All reagents and blood samples were prepared according to instruction, then samples were added to microwells. Later, the biotinylated protein was made and added in each microwell and incubated at room temperature. After washing, the sample was added with Streptavidin-Peroxidase conjugate and was incubated at room temperature. One more washing was carried out before the Chromogen substrate was put to each well. Wells were then incubated at room temperature. Stop solution was added before the result was read the result with flow cytometry in anti-Clq with levels of positive kit $>10 \mathrm{U} / \mathrm{mL}$ using anti-Clq ELISA kit (ORGENTEC Diagnostika GmbH, Mainz, Germany), $0-200 \mathrm{U} / \mathrm{mL}$.

Complement from the patient's serum was measured by MINIMEPH human complement with the ability to detect $\mathrm{C} 4$ level that ranges between 0.7 and $27 \mathrm{~g} / \mathrm{L}$ and $\mathrm{C} 3$ of $0.275-4.44 \mathrm{~g} / \mathrm{L}$.

Serum TNF- $\alpha$ levels were analyzed with ELISA method, then the result was read in ELISA reader as optical density. The result was converted to $\mathrm{pg} / \mathrm{mL}$ according to the instructions in the ELISA kit (Bender MedSystems, Vienna-Austria) that could detect $>2 \mathrm{pg} / \mathrm{mL}$.
ELISA method was used to measure the IL- 6 level. The reagents used were Human IL-6 (Quantikine ${ }^{\circledR}$ ELISA Human IL-6 Immunoassay, R\&D System, Inc. Catalog D6050), and the result was then read with ELISA reader. Normal serum IL-6 level is $>3.12 \mathrm{pg} / \mathrm{mL}$. This reagent is able to detect IL- $6 \geq 0.7 \mathrm{pg} / \mathrm{mL}$.

Before the measurement, microwells were stored and wrapped in aluminum foil at $2-8^{\circ} \mathrm{C}$, then washed with a wash buffer concentration of $400 \mu \mathrm{L}$ twice. After that, microwells were let stand for $10-15$ seconds and dried with absorbance. The dry microwells must not be placed upside down. Fifty $\mu \mathrm{L}$ biotin-conjugate was dripped into each well, $50 \mu \mathrm{L}$ serum was added from the samples, and the microwells were incubated for two hours at room temperature $\left(20^{\circ} \mathrm{C}\right)$. It was then covered with adhesive film and incubated at room temperature $\left(18-25^{\circ} \mathrm{C}\right)$.

After two hours, the adhesive film cover was removed, and the solution from the wells was disposed of. Microwells were washed three times using a $400 \mu \mathrm{L}$ wash buffer solution before 100 Streptavidin-HRP were added at all wells. Microwells were then covered with an adhesive film and incubated at room temperature $\left(18-25^{\circ} \mathrm{C}\right)$ for an hour. After that, microwells were washed three times with $400 \mu \mathrm{L}$ wash buffer solution again.

Furthermore, all microwells were added with $100 \mu \mathrm{L}$ TMB substrate and covered with aluminum foil to avoid light, and they were incubated at room temperature $\left(18-25^{\circ} \mathrm{C}\right)$ for 10 minutes. It was recommended to provide a $100 \mu \mathrm{L}$ stop solution in the dark if the wells with the highest concentration of the standard turned dark blue or dark. Finally, the results were generated within an hour by using a spectrophotometer with $450 \mathrm{~nm}$ wavelength.

The computer software of SPSS was used for data analysis. Mean and the standard deviation was determined on the quantitative data. This study aimed to determine the correlation between serum IL-6, TNF- $\alpha$, C3, C4, anti-dsDNA, and disease activity (SLAM score). Normality data was tested using the Kolmogorov-Smirnov test before the determination of the correlation. The interpretation of correlation test results was based on $p$-value, correlation strength, and direction of correlation. In this study, the correlation test between IL-6, TNF- $\alpha, C 3, C 4$, and anti-dsDNA serum with SLAM score resulted in $p=0.000$ (less than $0.05, \alpha=5 \%)$. The correlation strength ( $r$ ) of 0.00-0.199 and 0.20-0.399 showed a very weak and weak correlation, respectively. The r-value of 0.80 to 1.00 ; 0.60-0.799; and 0.40-0.599 showed a very strong, strong, and moderate correlation, respectively. Multivariate test (linear regression/Pearson's correlation) was performed to determine the correlation strength of SLAM with TNF- $\alpha$, IL- 6 , and anti-C1q autoantibodies. 


\section{RESULTS AND DISCUSSION}

The subjects' characteristics are shown in Table 1 . The highest education level was elementary school, and almost all the subjects came from a low economic level society. Weight loss and hair loss are the two most prominent symptoms. Clinical manifestations, such as musculoskeletal disorders, hematology disorders, and nephropathy, were prominent (Table 2). The results from laboratory tests and SLAM index showed that out of forty newly diagnosed SLE patients in Dr. Soetomo General Hospital Surabaya, 97.5\% of them were females with an average age of $30 \pm 8.1$ years, mean SLAM score of 20.98 \pm 6.7 , TNF- $\alpha$ of $3.9 \pm 1.15 \mathrm{pg} / \mathrm{mL}$, IL- 6 of $49.8 \pm 73.53 \mathrm{pg} / \mathrm{mL}$, anti-dsDNA level of $224.96 \pm 298.6 \mathrm{IU} / \mathrm{mL}$, anti-C1q of $42.18 \pm 52.16 \mathrm{IU} / \mathrm{mL}$, C3 level of $68.70 \pm 37.08 \mathrm{mg} / \mathrm{dL}$, and C4 level of $18.75 \pm 10.69 \mathrm{mg} / \mathrm{dL}$ (Table 3).

A correlation test using Spearman's correlation was performed to determine the correlation of cytokines, autoantibodies, and complement to disease activity

Table 1. Characteristics of SLE patients

\begin{tabular}{llcc}
\hline Characteristics & $\begin{array}{c}\text { Quantity } \\
(\mathbf{n = 4 0 )}\end{array}$ & $\begin{array}{c}\text { Percentages } \\
\text { (\%) }\end{array}$ \\
\hline Age & Mean $(30) \pm 8.1$ year & & 100 \\
Gender & Range $(16-47$ year) & & \\
& Male & 1 & 2.50 \\
Level of education & Female & 39 & 97.50 \\
& Bachelor & 4 & 10 \\
& Senior High School & 15 & 36.20 \\
Weight Loss & Junior High School & 10 & 25 \\
Fatigue & Elementary School & 11 & 10 \\
Fever & & 27 & 67.50 \\
Hair Loss & & 18 & \\
Hemoglobin & & 33 & 45 \\
& & 8 & 82.50 \\
C3 & $5-10 \mathrm{G} / \mathrm{dL}$ & 26 & 20 \\
C4 & $>10 \mathrm{G} / \mathrm{dL}$ & 6 & 65 \\
Anti-C1q & $<55 \mathrm{mg} / \mathrm{dL}(\mathrm{n}: 85-180 \mathrm{mg} / \mathrm{dL})$ & 26 & 15 \\
& $<10 \mathrm{mg} / \mathrm{dL}(\mathrm{n}: 10-40 \mathrm{mg} / \mathrm{dL})$ & 13 & 65 \\
& $\geq 10 \mathrm{U} / \mathrm{mL}$ & 33 & 32.5 \\
& $<10 \mathrm{U} / \mathrm{mL}$ & 9 & 77.5 \\
& & & 22.5 \\
\hline
\end{tabular}

Table 2. Patients clinical features based on 1997 ACR criteria

\begin{tabular}{lcc}
\hline American College Rheumatology Criteria & $\begin{array}{c}\text { Quantity } \\
(\mathbf{n = 4 0 )}\end{array}$ & Percentage \\
\hline Malar rash & 23 & 57.5 \\
Discoid rash & 8 & 20 \\
Oral ulcer & 24 & 60 \\
Photosensitivity & 7 & 17.5 \\
Arthritis & 32 & 80 \\
Serositis & 12 & 30 \\
Nephritis & 17 & 42.5 \\
Neuropsychiatric disorders & 6 & 15 \\
AIHA & 2 & 5 \\
Leukopenia & 9 & 25 \\
Lymphopenia & 35 & 87.5 \\
Thrombocytopenia & 21 & 52.5 \\
ANA (positive $\geq 20$ unit) & 27 & 67.5 \\
Anti-dsDNA (positive $\geq 92.6$ unit/mL) & 17 & 42.5 \\
\hline
\end{tabular}


Table 3. Mean level of cytokines, autoantibodies, complements, and SLAM score

\begin{tabular}{cccc}
\hline & Minimum & Maximum & Mean \pm SD \\
\hline TNF- $\alpha$ & 2.6 & 7.7 & $3.9 \pm 1.15$ \\
IL-6 & 3.10 & 355.10 & $49.8 \pm 73.53$ \\
Anti-dsDNA & 6 & 1403 & $224.96 \pm 298.6$ \\
Anti-C1q & 1.0 & 214.7 & $42.18 \pm 52.16$ \\
C3 & 22 & 149 & $68.70 \pm 37.08$ \\
C4 & 5 & 45 & $18.75 \pm 10.69$ \\
SLAM & 7 & 35 & $20.98 \pm 6.7$ \\
\hline
\end{tabular}

(Table 4). The results showed significant correlation of TNF- $\alpha(r=0.971, p<0.000)$, IL-6 $(r=0.835, p<0.000)$, and anti-C1q $(r=0.399 p<0.011)$ to SLAM index (disease activity). The multivariate test was performed using linear regression to determine the strength of the correlation between TNF- $\alpha$, IL- 6 , anti-C1q with SLAM index. TNF- $\alpha$ and SLAM had the strongest association $(r=0.891, p<0.000)$ (Table 5).

Table 4. Spearman's correlation test of cytokines, autoantibodies, and complements with disease activity (SLAM index)

\begin{tabular}{ccc}
\hline \multirow{2}{*}{ Antibodies } & \multicolumn{2}{c}{ SLAM Index } \\
\cline { 2 - 3 } & $\mathbf{p}$ & $\mathbf{r}$ \\
\hline TNF- $\alpha$ & 0.000 & 0.971 \\
IL-6 & 0.000 & 0.835 \\
Anti-C1q & 0.011 & 0.399 \\
C3 & -0.242 & 0.132 \\
C4 & -0.174 & 0.283 \\
Anti-dsDNA & 0.124 & 0.447 \\
\hline
\end{tabular}

Table 5. Strength of association between SLAM index with TNF- $\alpha$, IL- 6 , and anti-C1q using linear regression (Pearson's correlation)

\begin{tabular}{ccc}
\hline \multirow{2}{*}{ Antibodies } & \multicolumn{2}{c}{ SLAM index } \\
\cline { 2 - 3 } & $\mathbf{p}$ & $\mathbf{r}$ \\
\hline TNF- $\alpha$ & 0.000 & 0.891 \\
IL-6 & 0.000 & 0.608 \\
Anti-C1q & 0.007 & 0.389 \\
\hline
\end{tabular}

A strong correlation of SLAM score with TNF- $\alpha$ $(r=0.971, p<0.000)$ (Table 4) was found with a mean level of TNF- $\alpha$ of $3.9 \pm 1.15 \mathrm{mg} / \mathrm{dL}$. The strongest association was also found between both parameters, among others $(r=0.891, p<0.000)$ (Figure. 1). This result was different from previous studies of TNF- $\alpha$ on other ethnic groups such as Caucasian (median of $12.63 \mathrm{mg} / \mathrm{dL}$ ), Indian (mean of $63.00 \pm 67.28 \mathrm{mg} / \mathrm{dL}$ ), and Brazilian (median of 2.18
$\mathrm{IU} / \mathrm{dL}){ }^{4}$ What might cause these differences haven't yet been known. Still, genetic traits and environmental conditions might be some of them. Furthermore, Sabry et al. reported that the elevation of TNF- $\alpha$ level had the strongest correlation to lupus activity (SLEDAI index), especially lupus nephritis. ${ }^{5}$ McCarty also reported a significant relationship of elevated TNF- $\alpha$ levels to disease activity (SLEDAI index) with high five-year-period severity. ${ }^{6}$ This study showed a significant association between TNF- $\alpha$ and disease activities (organ-damage manifestations) such as arthritis, serositis, lupus nephritis, NPSLE, and anemia.

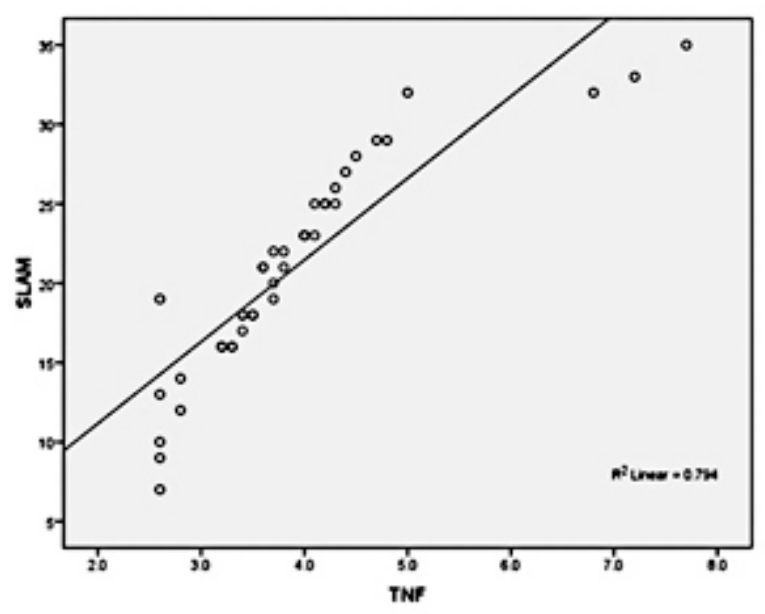

Figure 1. Strength of association between TNF- $\alpha$ and disease activity

In this study, TNF- $\alpha$ level represented cytokines' expressions, while anti-Clq was correlated to disease activity. On the other hand, complements and anti-dsDNA were not correlated with disease activity. The decrease in $\mathrm{C} 3$ and $\mathrm{C} 4$ levels can lead to more severe disease activity. Complements activity may vary among individuals, and they do not adequately represent an ongoing immune-response activity. This result hints at the complexity of SLE pathogenesis. According to the autoantibody theory, the formation of immune complexes triggers complement activation which can cause inflammation to multiple organs. ${ }^{7}$

An anti-inflammatory cytokine induces any inflammatory cytokine under normal condition. The cytokine imbalance triggers SLE to become more progressive. ${ }^{8}$ A study by Tackey et al. reported that some cytokines were associated with disease activity. Many other reviews said that cytokines hold a significant role in regulating the immune system. Cytokines in SLE play a role in the formation of autoantibodies and tolerance processes. Cytokines also affect the production of autoantibodies. Studies 
in the last decade reported that several cytokines were involved in SLE pathogenesis. Elevated IL- 6 enhances CRP and serum amyloid proteins that are involved in the tolerance process of apoptotic fragments. Both IL- 6 and TNF- $\alpha$ induce the secretion of acute-phase proteins which leads to the discharge of autoantibodies to systemic circulation.

It has been established that TNF- $\alpha$ holds a significant role in the pathogenesis of Rheumatoid Arthritis (RA). Therefore, the main goal of RA therapy is to maintain normal TNF- $\alpha$ levels to control disease progressivity. Meanwhile, studies on TNF- $\alpha$ role for SLE activity have been showing inconsistencies. Maury et al. showed no significant difference in TNF- $\alpha$ levels of $14 \mathrm{pg} / \mathrm{L}$ and inactive SLE with lupus nephritis. They obtained TNF- $\alpha$ levels of $24 \mathrm{pg} / \mathrm{L}$ in active RA from patients with synovial fluid, which was higher when compared to serum TNF- $\alpha$ in patients with SLE. Active SLE patients showed high levels of TNF- $\alpha$ that were almost identical with those of RA taken from synovial fluid. TNF- $\alpha$ also has similar roles in RA as proinflammatory cytokines. ${ }^{9}$ Compared to that study, Panafidina et al. showed higher IL- 6 and lower TNF- $\alpha$ levels than healthy controls. There was no correlation of disease activity to TNF- $\alpha$ and IL-16. They also reported that SLE patients during the active phase had decreased TNF- $\alpha$ level. They suspected that TNF-a in SLE was an immunoregulator. ${ }^{10}$ Idborg et al. reported that TNF- $\alpha$ correlated with disease activity, and they suggested that TNF- $\alpha$ could be used for biomarkers. ${ }^{11}$

In this study, the mean TNF- $\alpha$ level was at $3.9 \pm 1.15 \mathrm{pg} / \mathrm{L}$. Idborg et al. reported TNF- $\alpha$ levels of $4.5 \mathrm{pg} / \mathrm{L}$, similar to this study. ${ }^{11}$ Although TNF-a was not as high as in previous studies, it was presumed that TNF-a still has an inflammatory effect on inactive SLE. It was proven by the fact that $90 \%$ of subjects suffered from lymphopenia. This study found a prominent lymphopenia, which was suspected as a condition of apoptotic T-cells induced by TNF- $\alpha$. It was in accordance with the fact that TNF- $\alpha$ has a role in inducing apoptosis. ${ }^{12}$ According to previous studies, TNF- $\alpha$ induced autoantibody synthesis against cell components, and that process was enhanced by interferon-alpha (IFN- $\alpha$ ). It was proved by a study Palucka et al. that activity of TNF-a depends on TNF- $\alpha$ level, and both were simultaneously increased in active SLE. ${ }^{13,14}$

IL-6 is a pleiotropic cytokine mostly produced by a macrophage. It holds an essential role in regulating the immune and inflammatory systems. Garaud et al. reported that IL-6 increased CD5 expression in $\mathrm{B}$-cells, thus increasing the number of B-cells population. ${ }^{15}$ IL- 6 could induce TNF- $\alpha$, so that each cytokine affected each other. ${ }^{16}$ The cytokines level in each patient was different, presumably due to differences in clinical manifestations of SLE. ${ }^{17}$ IL- 6 and disease activity in this study were significantly correlated $(r=0.835, p<0.000)$ (Table 4) with an average IL-6 level of $49.8 \pm 73.53 \mathrm{pg} / \mathrm{mL}$ (Table 3) and showed a moderate strength of association (Figure 2). The mean concentration was slightly lower than Indian ethnicity $(63.00 \pm 67.28 \mathrm{pg} / \mathrm{dL})$, but way higher than another group like Brazilian $(1.5 \mathrm{pg} / \mathrm{mL})$ or a study on multi ethnicities $(1.64 \mathrm{pg} / \mathrm{mL}){ }^{4}$ Possible cause of these various results remained unknown.

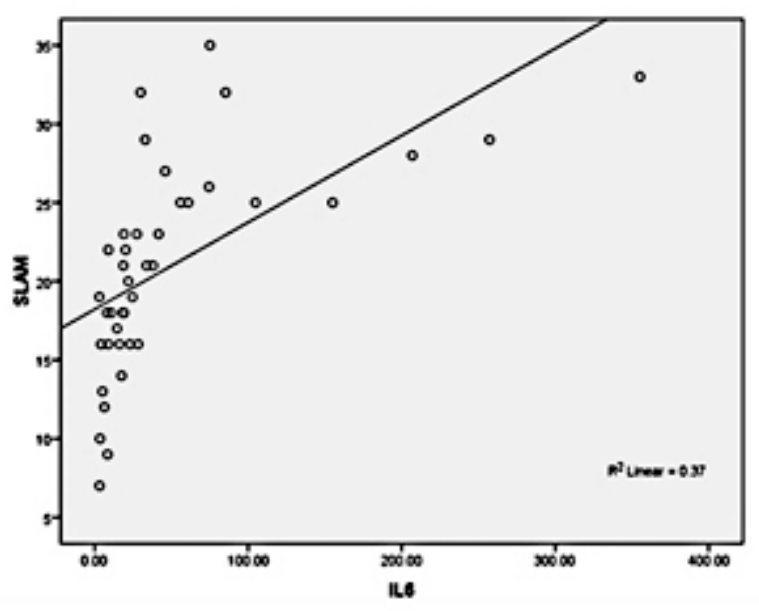

Figure 2. Strength of association between IL-6 and disease activity

According to a study by Enocsson et al., the elevation of IL- 6 level was correlated to disease activity in SLE $(r=0.389 P<0.013){ }^{18}$ William stated that IL- 6 was not correlated to CRP in lupus, and study Richard on an animal study reported that IL-6 induced the synthesis of anti-dsDNA. The formation of anti-dsDNA was highly dependent on IL-6. ${ }^{19}$ IL-6 allegedly depicts a localized inflammation, especially in kidneys. The role of antibodies in the inflammation process is most apparent in the kidneys where antibodies activate complement and cause inflammation; however, this process is systemically undetected.

It has been reported that anti-dsDNA's association with disease activity and its ability to predict SLE recurrence are minimal, and anti-dsDNA was not the only antibody related to SLE activity. Anti-dsDNA cannot be used as a guide for determining SLE disease activity because it depends on the assay technique. Positive anti-dsDNA does not always represent SLE, and negative anti-dsDNA does not exclude SLE diagnosis. ${ }^{20}$ Anti-dsDNA is a very specific antibody marker for active SLE, which is 
found abundantly in renal tissue. ${ }^{8}$ A study on animals showed that the incidence of glomerulonephritis was related to the anti-dsDNA level. ${ }^{21} \mathrm{~A}$ cohort study reported that a high level of anti-dsDNA was associated with the severity and the progressivity of kidney damage. ${ }^{22} \mathrm{M}$ Lopez-Hoyos et al. obtained an anti-dsDNA level of $59.3+8.7 \mathrm{IU} / \mathrm{mL}$ (measured by ELISA dsDNA) in active lupus. ${ }^{23}$ This study found the mean anti-dsDNA concentration of $224.96 \pm 298.6$ $\mathrm{IU} / \mathrm{mL}$, suggesting a higher result than previous studies. These differences were suspected to be related to genetic factors.

The role of complements in SLE is complex. Complement activation causes a decrease in $\mathrm{C} 3$ and C4 levels in active SLE, but their concentration will rapidly rise to its initial level after the activation process is complete. C4 rises back to its normal level faster than C3 to prevent further complement activation. It is widely known that complement holds a significant role in inflammation and organ damage associated with an autoimmune or immune complex-mediated disease. ${ }^{24} \mathrm{~A}$ study by Nguyen on inactive SLE patients obtained the average $\mathrm{C} 3$ and C4 levels of $37.50 \mathrm{mg} / \mathrm{dL}$ and $22.29 \mathrm{mg} / \mathrm{dL}$. Therefore, $\mathrm{C} 3$ and C4 could be used as diagnostic instruments to assess disease activity. ${ }^{25}$ Narayanan et al. also reported a C3 average level of $81.08 \mathrm{mg} / \mathrm{dL}$ and a C4 level of $15.05 \mathrm{mg} / \mathrm{dL}{ }^{26}$ Furthermore, a study by Einav et al. reported that $\mathrm{C} 4$ was protective against lupus. At the same time, it was also strongly associated with $\mathrm{C} 3$ in terms of its relation to disease activity. ${ }^{27}$ Meanwhile, researchers found that the mean C 3 and C4 level of $68.70 \pm 37.08 \mathrm{mg} / \mathrm{dL}$, and $18.75 \pm 10.69$ $\mathrm{mg} / \mathrm{dL}$, respectively. In lupus, complements exhibit duality in which they are related to tissue damage, but on the other hand, they also protect tissues against inflammation due to immune complexes.

Anti-C1q is a component in the classic pathway of complement activation that generally serves to neutralize immune complexes, and correlated to risks and activity of lupus. ${ }^{28,29}$ Anti-C1q was suspected of having other biological functions that play a role in facilitating and inhibiting the pathogenesis of lupus. Lood et al. reported that the novel feature of anti-C1q regulates the immune complex that induces the production of IFN- $\alpha$ and other cytokines in the plasmacytoid dendritic cells. Anti-C1q allegedly has various roles in the pathogenesis of SLE and its clinical manifestations. ${ }^{30}$ Anti-Clq level in this study was shown to be significantly correlated with SLAM $(r=0.399 p<0.011)$ (Table 4) with a mean concentration of $42.18 \pm 52.16 \mathrm{IU} / \mathrm{mL}$. This study also found that anti-C1q had a positive correlation to disease activity $(r=0.389, p=0.007)$ (Figure 3), although it wasn't as strong as TNF- $\alpha$ or IL-6 (Table 5). It was following a study by Moura et al., which found the worsening of SLE activity following the elevation of anti-C1q level. ${ }^{29}$

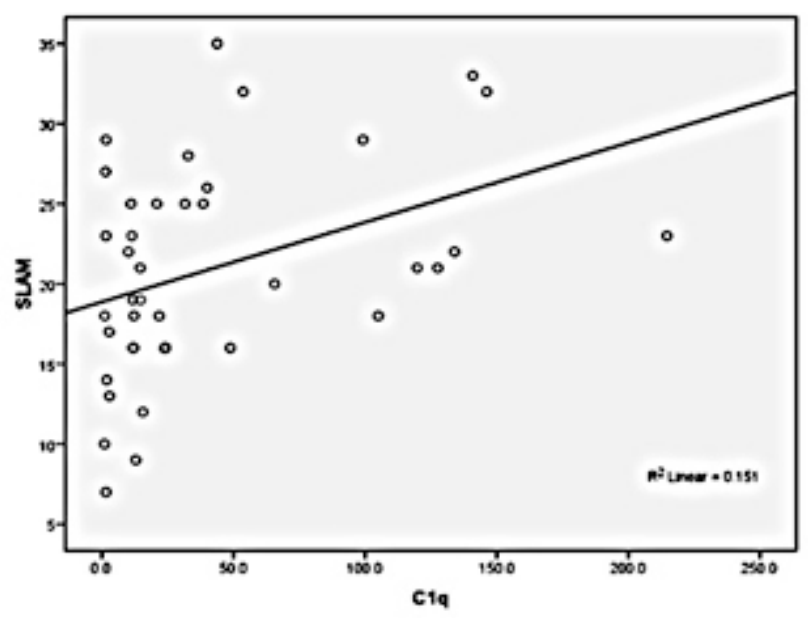

Figure 3. Strength of association between anti-C1q and disease activity

Cytokines showed an indisputable role in the inflammation process and autoimmune disease. Their pleiotropic effect enables their components to have both synergistic or antagonistic to each other. In addition to cytokines, autoantibodies and complements are also involved in the inflammation process and tissue injury through the complement-activation cascade. However, it is challenging to determine cytokines, autoantibodies, and complements involved in the pathogenesis of SLE. It raised a question on immunological components that integrate as an immune system.

\section{CONCLUSION AND SUGGESTION}

IL-6, TNF- $\alpha$, and anti-C1q were correlated to disease activity in SLE patients from the Javanese population, although their roles to the pathogenesis of specific clinical manifestations remained unclear. Therefore, it was necessary to perform a further cohort study to evaluate the role of cytokines in active and inactive diseases.

\section{Acknowledgment}

Authors would like to acknowledge Poernomo Boedi Setiawan, dr., Sp.PD-KGEH, as Head of Internal Medicine Department, Airlangga University; the Department of Clinical Pathology, Airlangga University; Medical Research Unit of Airlangga 
University; and Harsono, dr., as Director of Dr. Soetomo General Hospital, Surabaya.

\section{REFERENCES}

1. Mok CC, Lau CS. Pathogenesis of systemic lupus erythematosus. J Clin Pathol, 2003; 481-90.

2. Tackey E, Lipsky PE, Illei GG. Rationale for interleukin-6 blockade in systemic lupus erythematosus. Lupus, 2004; 13(5): 339-43.

3. Romero-Diaz J, Isenberg D, Ramsey-Goldman R. Measures of adult systemic lupus erythematosus: updated version of British Isles Lupus Assessment Group (BILAG 2004), European Consensus Lupus Activity Measurements (ECLAM), Systemic Lupus Activity Measure, Revised (SLAM-R), Systemic Lupus Activity Questionnaire for Population Studies (SLAQ), Systemic Lupus Erythematosus Disease Activity Index 2000 (SLEDAI-2K), and Systemic Lupus International Collaborating Clinics/American College of Rheumatology Damage Index (SDI). Arthritis Care \& Research. 2011;63(11): S37-46.

4. Umare V, Pradhan V, Nadkar M, Rajadhyaksha A, Patwardhan $\mathrm{M}$, Ghosh KK, et al. Effect of proinflammatory cytokines (IL-6, TNF-\&\#x3b1; and IL-1\&\#x3b2;) on clinical manifestations in Indian SLE patients. Mediators of Inflammation, 2014; 2014: 8.

5. Sabry A, Sheashaa H, El-Husseini A, Mahmoud K, Eldahshan KF, George SK, et al. Proinflammatory cytokines (TNF-alpha and IL-6) in Egyptian patients with SLE: Its correlation with disease activity. Cytokine, 2006; 35(3-4): 148-53.

6. McCarthy EM, Smith S, Lee RZ, Cunnane G, Doran MF, Donnelly $S$, et al. The association of cytokines with disease activity and damage scores in systemic lupus erythematosus patients. Rheumatology (Oxford, England), 2014; 53(9): 1586-94.

7. Giles BM, Boackle SA. Linking complement and anti-dsDNA antibodies in the pathogenesis of systemic lupus erythematosus. Immunologic research, 2013; 55(1-3): 10-21.

8. Illei GG, Tackey E, Lapteva L, Lipsky PE. Biomarkers in systemic lupus erythematosus: II. Markers of disease activity. Arthritis and Rheumatism, 2004; 50(7): 2048-65.

9. Maury CPJ, Teppo AM. Tumor necrosis factor in the serum of patients with systemic lupus erythematosus. Arthritis \& Rheumatism, 1989; 32(2): 146-50.

10. Panafidina TA, Popkova TV, Novikov AA, Nasonov EL. AB0630 expression of TNF-? and IL- 6 in systemic lupus erythematosus: Relationship with disease activity. Annals of the Rheumatic Diseases, 2018; 77(2): 1462-3.

11. Idborg $H$, Eketjäll $S$, Pettersson $S$, Gustafsson JT, Zickert A, Kvarnström $M$, et al. TNF- $\alpha$ and plasma albumin as biomarkers of disease activity in systemic lupus erythematosus. Lupus Science \& Amp. Medicine; 2018; 5(1): e000260.

12. Chen G, Goeddel DV. TNF-R1 signaling: A beautiful pathway. Science (New York, NY). 2002; 296(5573): 1634-5.
13. Palucka AK, Blanck JP, Bennett L, Pascual V, Banchereau J. Cross-regulation of TNF and IFN- $\alpha$ in autoimmune diseases. Proc Natl Acad Sci USA, 2005; 3372-7.

14. Gabay C, Cakir N, Moral F, Roux-Lombard P, Meyer O, Dayer JM, et al. Circulating levels of tumor necrosis factor soluble receptors in systemic lupus erythematosus are significantly higher than in other rheumatic diseases and correlate with disease activity. The Journal of Rheumatology, 1997; 24(2): 303-8.

15. Garaud S, Le Dantec C, Jousse-Joulin S, HanrotelSaliou C, Saraux A, Mageed RA, et al. IL- 6 modulates CD5 expression in B-cells from patients with lupus by regulating DNA methylation. The Journal of Immunology, 2009; 182(9): 5623-32.

16. Charles P, Elliott MJ, Davis D, Potter A, Kalden JR, Antoni $C$, et al. Regulation of cytokines, cytokine inhibitors, and acute-phase proteins following antiTNF-alpha therapy in rheumatoid arthritis. Journal of Immunology (Baltimore, Md : 1950). 1999; 163(3): 1521-8.

17. Jacob N, Stohl W. Cytokine disturbances in systemic lupus erythematosus. Arthritis Research \& Therapy. 2011; 13(4): 228.

18. Enocsson $H$, Sjowall $C$, Kastbom A, Skogh $T$, Eloranta $\mathrm{ML}$, Ronnblom $\mathrm{L}$, et al. Association of serum C-reactive protein levels with lupus disease activity in the absence of measurable interferon-alpha and a C-reactive protein gene variant. Arthritis \& Rheumatology (Hoboken, NJ). 2014; 66(6): 1568-73.

19. Richards HB, Satoh M, Shaw M, Libert C, Poli V, Reeves WH. Interleukin- 6 dependence of anti-DNA antibody production: Evidence for Two pathways of autoantibody formation in pristane-induced lupus. The Journal of Experimental Medicine, 1998; 188(5): 985-90.

20. Fu SM, Dai C, Zhao Z, Gaskin F. Anti-dsDNA Antibodies are one of the many autoantibodies in systemic lupus erythematosus. F1000Research, 2015; 4 (F1000 Faculty Rev).

21. Okamura M, Kanayama Y, Amastu K, Negoro N, Kohda $\mathrm{S}$, Takeda $\mathrm{T}$, et al. Significance of Enzyme Linked Immunosorbent Assay (ELISA) for antibodies to double stranded and single stranded DNA in patients with lupus nephritis: correlation with severity of renal histology. Annals of the Rheumatic Diseases, 1993; 52(1): 14-20.

22. MacGowan JR, Ellis $S$, Griffiths $M$, Isenberg DA. Retrospective analysis of outcome in a cohort of patients with lupus nephritis treated between 1977 and 1999. Rheumatology (Oxford, England). 2002; 41(9): 981-7.

23. López-Hoyos M, Cabeza R, Martínez-Taboada VM, Crespo J, SanSegundo D, Blanco R, et al. Clinical disease activity and titers of anti-dsDNA antibodies measured by an automated immunofluorescence assay in patients with systemic lupus erythematosus. Lupus, 2005; 14(7): 505-9.

24. Sturfelt G, Truedsson L. Complement in the immunopathogenesis of rheumatic disease. Nature 
Reviews Rheumatology, 2012; 8(8):458-68.

25. Nguyen CP, Cao VV, Feher J, Gergely P. Correlation between the levels of antinuclear antibodies, antiDNA antibodies, and complement in systemic lupus erythematosus. Acta Medica Hungarica, 1988; 45(2): 145-59.

26. Narayanan K, Marwaha V, Shanmuganandan K, Shankar S. Correlation between systemic lupus erythematosus disease activity index, C3, C4 and anti-dsDNA antibodies. Medical Journal, Armed Forces India, 2010; 66(2): 102-7.

27. Einav S, Pozdnyakova OO, Ma M, Carroll MC. Complement $\mathrm{C} 4$ is protective for lupus disease independent of C3. Journal of Immunology (Baltimore,
Md: 1950). 2002; 168(3): 1036-41.

28. Walport MJ. Complement and systemic lupus erythematosus. Arthritis Research, 2002; 4(3): S279-93.

29. Moura CG, Lima I, Barbosa L, Athanazio D, Reis E, Reis $\mathrm{M}$, et al. Anti-Clq antibodies: association with nephritis and disease activity in systemic lupus erythematosus. Journal of Clinical Laboratory Analysis, 2009; 23(1): 19-23.

30. Lood C, Gullstrand B, Truedsson L, Olin AI, Alm GV, Rönnblom $\mathrm{L}$, et al. $\mathrm{C} 1 \mathrm{q}$ inhibits immune complexinduced interferon-? production in plasmacytoid dendritic cells: A novel link between $\mathrm{Clq}$ deficiency and systemic lupus erythematosus pathogenesis. Arthritis \& Rheumatism, 2009; 60(10): 3081-90. 